\title{
Luminescent silica microagglomerates, synthesis, and environmental testing
}

\author{
Lance Hubbard (D), Clara Reed, Nicolas Uhnak, Ryan Sumner, Trevor Cell, Erin Kinney, Nathaniel Smith, \\ Caleb Allen, Michael Foxe, April Carman, Pacific Northwest National Laboratory, P.0. Box 999, Richland, WA 99352, USA \\ Address all correspondence to Lance Hubbard at lance.hubbard@pnnl.gov
}

(Received 22 October 2021; accepted 29 December 2021; published online: 24 January 2022)

\section{Abstract}

Tracking mass through harsh environments requires surrogate particles that withstand the event and endure until sampling. Silica-covered quantum dots have been shown to withstand a range of environmental pHs from months to years; in this work they are shown to endure in anticipated local environments. Two methods of particle synthesis were employed to produce luminescent silica with particle diameters $0.1-4 \mu \mathrm{m}$. These tracer particles scale for mass production, tolerate harsh environments, and endure in debris. They could be deployed in places such as chemical explosions, industrial processes, geologic test beds, oil and gas fields, nuclear reactors, and geothermal plants to track mass under harsh conditions.

\section{Introduction}

Particulate tracking through chemical explosions and other harsh environments requires surrogate particles that withstand the dynamics of the event and endure in the local environment until sampling is possible. ${ }^{[1-3]}$ The authors have reported previously on the survivability of ruggedized particulate tracers during explosions. ${ }^{[4]}$ Present results inform the survivability of silica-coated luminescent tracer particles in the environment as well as synthesis paths to control particle size while maintaining luminescent intensity. The ability to control particle size and emissive color, and to ensure the tracer's long-lasting endurance provides an elegant solution for tracking mass through harsh environments.

Tracers for harsh environments need to endure until sampling, measurement, and analysis take place. More traditional, organic tracers such as fluorescent dyes can be degraded by reactive environments (e.g., burnt). Moving from an organicbased tracer to a particulate such as inorganic quantum dots can increase the survivability of a tracer but still lead to large degradations as the environment directly attacks the particulates. ${ }^{[4]}$ To increase a tracer's environmental endurance, a chemically inert, signal-transmissive layer can be added to protect the tracer from the hostile environment (i.e., serve as a shield). This layer of the tracer protects the inner signal-producing portion while allowing the signal to be received during sampling and debris analysis. In previous work, shielding zinc sulfide (ZnS:Mn) quantum dots in 100-nm-thick silica shells lead to a two-to-three-fold increase in luminescent intensity post-explosion when compared to bare quantum dots. ${ }^{[4]}$ As previously reported results have explored the ruggedization of silica-covered $\mathrm{ZnS}$ :Mn quantum-dot tracers, this work expands the scope to explore the environmental endurance of the ruggedized tracers.
The local environment around a tracer particle plays a large role in the chemical condition and luminescent intensity of the tracer. ${ }^{[5-10]}$ The dispersant's $\mathrm{pH}$ has been found to play a large role in the stability of the silica shell. ${ }^{[7,11]}$ Here, we tested the environmental endurance of the tracers from $\mathrm{pH} 3$ to $\mathrm{pH} 13$, as the outer silica shell's state varies from metastable to active dissolution over this $\mathrm{pH}$ range. ${ }^{[11]}$ Producing a particle where size and luminescent intensity are controllable becomes the next step in creating a deployable particulate tag.

Previous work to make luminescent silica microspheres has resulted in microparticles with diminished luminescence compared to quantum dots in suspension. ${ }^{[12-14]}$ Silica shells from 10-100 nm thick have caused intensity decreases of more than $50 \%{ }^{[15,16]}$ As single silica shells can diminish luminescent emissions, an agglomerated synthesis method was sought for micron-scale diameter particles that are controllable in size and maintain luminescent intensity.

Micron-scale silica spheres have been made since the late 1960s by the Stöber method. ${ }^{[17]}$ Agglomerated silica particles made by the Stöber method have received far less attention until recently ${ }^{[18]}$ when their specific porous properties have been sought. One of the methods to make agglomerated silica particles is by the iterative stepwise addition of reagents. Iterative synthesis of the particles allows for control of both the smaller silica shell around the quantum dots and their overall agglomerated microparticle size.

Two methods to create luminescent silica-covered quantum dots ("silication") were employed in this work. For particles less than one micron in diameter, multiple shells of silica were grown around the quantum dots to make particles with known size ranges. As luminescent intensity was diminished for single silica shell particles larger than $1 \mu \mathrm{m}$, an iterative reagent addition method was employed to make agglomerated 
microscale particles that maintain their luminescent intensity. By employing both particle synthesis techniques, luminescent silica-shelled tracer particles have been produced with mean diameters from 0.1 to $4 \mu \mathrm{m}$.

In this work, the synthesis of $0.1-4-\mu \mathrm{m}$-diameter silicacovered $\mathrm{ZnS}: \mathrm{Mn}$-based tracers is presented and their response to environmental $\mathrm{pH}$ is examined. Specifically, the authors hypothesize that the luminescence intensity of $3-\mathrm{mg} / \mathrm{mL}$-concentration, 1- $\mu \mathrm{m}$-diameter microagglomerates will be above the detection threshold of an Ocean Insight HDX detector (Model: OCEAN-HDX-UV-VIS) after 40 days of $\mathrm{pH} 3$ or higher exposure. The ability to make silica-covered luminescent tracers with tailorable size, bright emissions, and the ability to endure for months to years is important for applications where the tracer will be exposed to harsh conditions until collection and measurement are possible.

\section{Experimental materials and methods Materials}

Ethylene glycol (CAS: 107-21-1,>99\%), zinc (II) acetate (CAS: 557-34-6, 99.99\%), methacrylic acid (CAS: 79-41-4, 99\%), manganese (II) acetate (CAS: 638-38-0, 98\%), polyethylene glycol-8000 (PEG, CAS: 25322-68-3, 99\%), sodium sulfide (NaS, CAS: 1313-82-2, 99\%), 3-mercaptopropyltrimethoxysilane (MPTMS, CAS: 4420-74-0, 95\%), tetraethylorthosilicate (TEOS, CAS: 78-10-4, 98\%), ammonium hydroxide (CAS: 1336-21-6, 28-30\% $\mathrm{NH}_{3}$ basis), ethanol (CAS: 64-17-5, 99.5\%), ascorbic acid (CAS: 50-81-7, 99\%), and sodium hydroxide (CAS: 1310-73-2,>98\%) were acquired from Sigma-Aldrich or were legacy chemicals acquired from Pacific Northwest National Laboratory dry storage and were used without further purification. All chemicals and solvents were of reagent grade.

\section{Luminescent nanoparticle synthesis}

The quantum-dot synthesis followed a previously published method. ${ }^{[4]}$ The synthesis method is briefly described as follows.

The ZnS:Mn nanoparticles were synthesized by adding $104 \mathrm{~mL}$ of ethylene glycol into a 500-mL Erlenmeyer flask, followed by $0.97 \mathrm{~g}$ of zinc acetate $\left(\mathrm{Zn}(\mathrm{Ac})_{2}\right)$ and a polytetrafluoroethylene (PTFE)-coated stir bar. Into this stirring mixture, $0.78 \mathrm{~mL}$ of methacrylic acid was added. This was followed by the addition of $0.60 \mathrm{~mL}$ of a $1.8 \mathrm{mg} / \mathrm{mL} \mathrm{Mn}(\mathrm{Ac})_{2}$ solution, a $0.1 \% \mathrm{~mol}$ ratio with $\mathrm{Zn}(\mathrm{Ac})_{2}$. The addition of $3.12 \mathrm{~g}$ of PEG8000 was added to the stirring mixture. The solution temperature was raised to near-boiling. Over $10 \mathrm{~min} 1.77 \mathrm{~g}$ total of $\mathrm{NaS}$ was added slowly by means of 20 evenly spaced and divided additions. Once the $\mathrm{NaS}$ was completely added, the solution was boiled, adjusting the solution volume as needed to maintain a steady liquid level, for $2 \mathrm{~h}$. The slurry was transferred and split roughly equally among three $50-\mathrm{mL}$ centrifuge tubes, centrifuged for $15 \mathrm{~min}$, and the supernatant was removed. The solid was rinsed three times with $25 \mathrm{~mL}$ deionized water by adding the water, vortex mixing for $2 \mathrm{~min}$, centrifuging for $5 \mathrm{~min}$, and removing the supernatant. The nanoparticles were stored in $10 \mathrm{~mL}$ of deionized water until use for further synthesis.

\section{Submicron diameter silica coating}

A small portion of the nanoparticles, $0.1 \mathrm{~g}$, was transferred into a $50-\mathrm{mL}$ centrifuge tube. Into the vial, $10 \mathrm{~mL}$ of water was added and vortex mixed at 3200 rotations per minute (rpm) for $2 \mathrm{~min}$. This was followed by the addition of $6 \mathrm{~mL}$ of ethanol and $30 \mu \mathrm{L}$ of MPTMS. This mixture was vortexed for $1 \mathrm{~min}$ on high (3200 rpm) speed. To this mixture, $1.2 \mathrm{~mL}$ of TEOS and $0.6 \mathrm{~mL}$ of $50 \%$ ammonium hydroxide were added to the mixture and sonicated $(40 \mathrm{~W}, 40 \mathrm{kHz})$ for $1 \mathrm{~h}$ at $60^{\circ} \mathrm{C}$. At the 1-h mark, the flask was centrifuged for $10 \mathrm{~min}$, the supernatant was disposed, and the process was repeated three times, rinsing with $20 \mathrm{~mL}$ of water in each rinse. The procedure was repeated up to three times to build up an increasingly thick layer of silica around the quantum dots.

\section{Multimicron diameter silica coating and agglomeration}

Once the nanoparticle synthesis was complete, $16 \mathrm{mg}$ of nanoparticles was added to a $50-\mathrm{mL}$ centrifuge tube. Solvents were added: first $4 \mathrm{~mL}$ ethanol, then $6 \mathrm{~mL}$ of water followed by 5 min of vortex mixing at $3200 \mathrm{rpm}$. Next, $5 \mu \mathrm{L}$ of MPTMS was added to the mixture followed by 5 more minutes of vortex mixing. Then $300 \mu \mathrm{L}$ of TEOS was added. A stir rod was added to each tube and the mixture was stirred at $1500 \mathrm{rpm}$, while $100 \mathrm{uL}$ of ammonium hydroxide was added to each tube. At the 5-min mark, after ammonium hydroxide was added, 100 $\mu \mathrm{L}$ of TEOS was added to the suspension. At $35 \mathrm{~min}$ an additional $100 \mu \mathrm{L}$ of TEOS was added. Another $50 \mu \mathrm{L}$ of TEOS was added at $65 \mathrm{~min}$ and again at $125 \mathrm{~min}$.

\section{Synthesis of monodisperse silica-coated particles}

Synthesis of 1- $\mu \mathrm{m}$-diameter monodisperse-coated quantum dots was performed by following the synthesis procedure of Zhao et al. ${ }^{[19]}$ with the process parameters set for $1 \mu \mathrm{m}$ spheres. Initial silica-covered quantum dots were introduced as the seed particles by the adding $16 \mathrm{mg}$ of the nanoparticles followed by $5 \mu \mathrm{L}$ of MPTMS. The locations of the quantum dots were verified with fluorescence microscopy.

\section{Characterization tools and parameters}

The emission spectra were taken from standard optical cuvettes with an Ocean Insights HDX spectrometer with vendor-supplied fiber optics/collimating lenses and an additively manufactured cuvette/optics holder. Excitation of the suspensions was achieved with a Mightex $325 \mathrm{~nm}$ fiber-coupled LED (GCS0325-03-A0510) set to maximum brightness. Care was taken to equalize the thermal and power conditions of the measurements allowing for direct intensity comparison. 
Particle sizing was performed by three methods, depending on the particle size. Scanning electron microscope (SEM) images were taken on a Helios 600 for particle diameters below $1 \mu \mathrm{m}$. The bias was set to $10 \mathrm{kV}$ and a working distance of 4-8 mm. Dynamic light scattering (DLS) was performed with a NanoBrook from Brookhaven Instruments, at ambient temperature for all diameters. Fluorescence microscopy was performed with an Omax 40X-2500X Advanced EPI-Fluorescence Trinocular Biological Microscope, and a Dinolite Fluorescent Digital Microscope, AM4115T-CFVW for particle diameters larger than $1 \mu \mathrm{m}$.

\section{Results}

The spectroscopic evaluation of luminescent intensity shows that the microagglomerates produce significantly more luminescence when compared to either a mix of quantum dots and monodisperse silica or single-shelled particles with internal quantum dots, shown in Fig. 1. The microscopic and fluoromicroscopic images comparing the particle types can be seen in the Supplemental Information Fig. S1. As can be seen in Fig. 1, the agglomerated particles are more luminescent when compared against the unshelled quantum dots than other core-shell configurations and mixtures.

The two silication methods produced silica-shelled particles with thicknesses from 0.1 to $4 \mu \mathrm{m}$. Layering silica shells was found to increase the sizes of the particles for submicron diameters, as measured using DLS. The first shell resulted in particles with a diameter of around $152 \mu \mathrm{m}$, the second $230 \mu \mathrm{m}$, and the third $650 \mu \mathrm{m}$, as determined from analysis of the normal distribution of the curves. When the fourth round of silication was completed, the luminescence of the resulting particles was diminished like that presented for the monodisperse core-shell particles in Fig. 1. The microagglomeration method was then employed to produce larger-diameter particles and maintain the luminescent properties of the tracer.

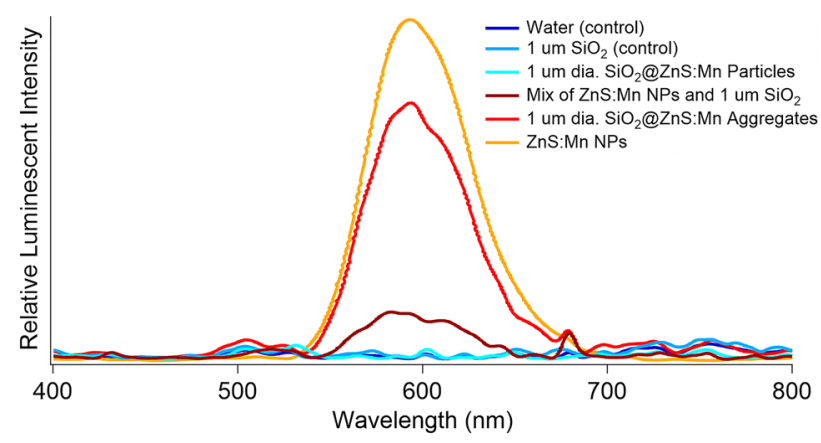

Figure 1. Photoluminescence $(\mathrm{PL})$ of the quantum dots encapsulated in 1- $\mu \mathrm{m}$-diameter core-shell particles and backgrounds showing microagglomerated silica particles $\left(\mathrm{SiO}_{2} @ \mathrm{ZnS}: \mathrm{Mn}\right.$, red $)$ as retaining the most quantum dots-based photoluminescence (orange) relative to linear mixtures of dot and particles (dark red), and single-shelled micron-scale particles (light blue).
The iterative addition of reagents produced microagglomerates with sizes from 1 to $4 \mu \mathrm{m}$ in diameter. The full width at half maximum (FWHM) of the particles expanded with each iterative silication step, which is graphically depicted in Supplemental Information Fig. S2 along with a scanning electron micrograph of the $1-\mu \mathrm{m}$-diameter agglomerates. The compiled particle diameters from 0.1 to $4 \mu \mathrm{m}$ can be seen in Fig. 2 .

The environmental impact on the luminescence of the tracers was determined by exposure to varying $\mathrm{pH}$ suspensions. The luminescent intensity of $1 \mu \mathrm{m}$ agglomerated particles was measured. The $\mathrm{pH}$ was adjusted for each suspension by the addition of ascorbic acid (for $\mathrm{pH}<7$ ) and sodium hydroxide (for $\mathrm{pH}>7$ ) to deionized water. As can be seen in Fig. 3, all suspensions started with similar intensities, and a clear distinction can be seen evolving between the samples based on dispersion $\mathrm{pH}$. Generally, in dispersions with values from $\mathrm{pH} 7$ to $\mathrm{pH} 13$, exposure time increases luminescent intensity, dispersions with

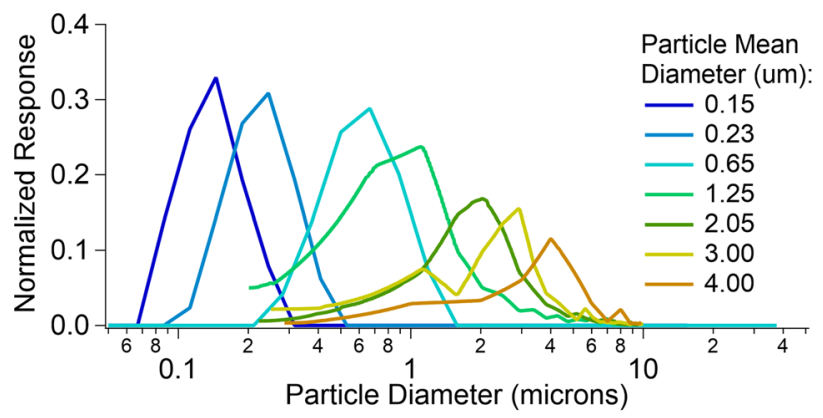

Figure 2. The particle distributions of the luminescent microspheres. Data below $1 \mu \mathrm{m}$ diameter were measured with DLS, while responses larger than $1 \mu \mathrm{m}$ were evaluated by fluorescent imaging.
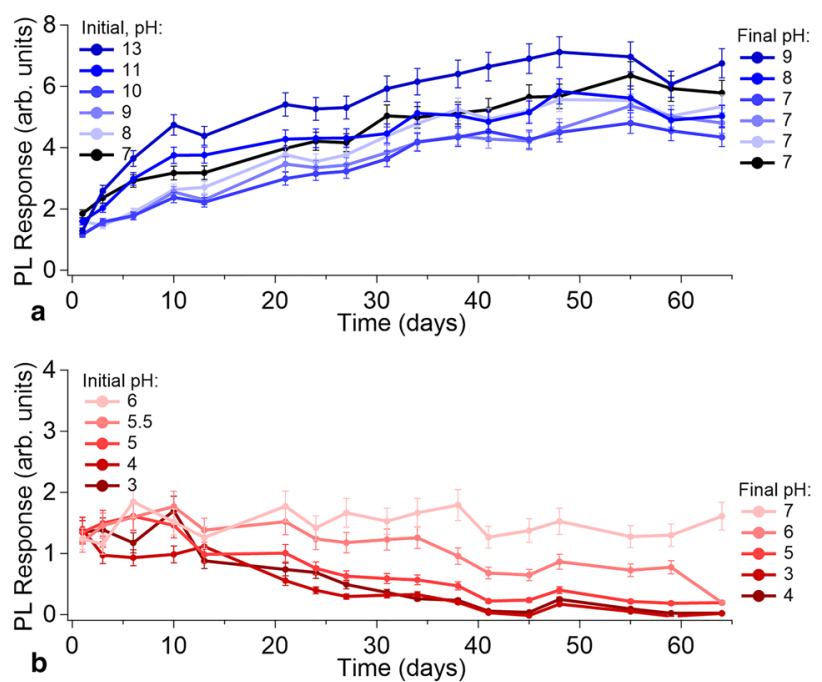

Figure 3. The integrated PL intensity of $3 \mathrm{mg} / \mathrm{mL} 1-\mu \mathrm{m}$-diameter microagglomerated particles vs. time over a range of suspension $\mathrm{pH}$. The solution's starting and final $\mathrm{pH}$ are listed. (a) the control and basic suspensions and (b) acidic suspensions. 
pH 6 show little change, and dispersions with pHs from 5 to 3 decrease the particles' luminescent intensity over 1 to 2 months. Ions in the liquid were consumed as, generally, the final $\mathrm{pH}$ was more moderate than the initial $\mathrm{pH}$. The environment around the tracer influences the tracer's luminescent intensity depending on the local $\mathrm{pH}$.

Supplemental Information Fig. S3 corroborates the intensity enhancement seen in Fig. 3(a). In this comparison, 100-nmdiameter silica-covered particles around manganese-doped zinc sulfide quantum dots, which had been molecularly bonded to 485-nm-emitting commercial strontium aluminate in deionized water, ${ }^{[4]}$ were compared over 2 years. Peaks associated with the inner quantum dots ${ }^{[20]}$ were seen to be enhanced while the emission peak of the aluminate at $485 \mathrm{~nm}$ remained constant.

\section{Discussion}

Tracer particulates for harsh environments need to be tailorable in size. As the results in Fig. 2 show, the two-particle synthesis methods enable tracers to be made with mean particle sizes from 0.1 to $4 \mu \mathrm{m}$. The need for switching from a single silica shell to an agglomerated microparticle is made evident by comparing the luminescent intensities seen in Fig. 1. Agglomerated core-shell silica particles maintain a bright luminescence, while single-shelled microparticles do not. The luminescence of the agglomerates is even greater than that of a mixture of quantum dots and microsilica particles. As tracers can be made in any needed size range, their environmental endurance was then tested.

Initial work on quantum dots inside silica particles showed that basic $\mathrm{pH}$ ranges enhance emission. ${ }^{[12]}$ The results presented in Fig. 3(a) corroborate the previous work and show that the emission intensity increases over several months of time. The emission intensity begins to stabilize with time and, as is seen in Fig. S3, after 2 years the same silica-covered sample has enhanced emission peaks that match those of the manganesedoped zinc sulfide quantum dots. ${ }^{[21]}$ In neutral to basic solutions, the agglomerated silica particles maintain a luminescent signature that increases with time (up to a point) and the emission is evident on a time scale of years.

In acidic solutions ( $\mathrm{pH} 3-7)$, the agglomerated particles are stable for at least 40 days (Fig. 3(b)). As zinc sulfide is photocatalytically active in the presence of sodium and acids, ${ }^{[22,23]}$ the results may indicate the diffusion of the hydrogen through the silica shell coupled with the consumption of the zinc sulfide to zinc oxide. The agglomerated particles lose their luminescent intensity after 40 days of exposure at $\mathrm{pH} 3$ to $\mathrm{pH} 5$. The particles in environments from $\mathrm{pH} 5.5$ to $\mathrm{pH} 6$ maintain their luminescent intensity for at least 60 days, perhaps more. In acidic environments, the agglomerated particles are stable on a time scale of months, before tending to decrease intensity.

As explosive residues can have varying $\mathrm{pHs}$ when interacting with the environment, ${ }^{[24]}$ a luminescent tag needs to be able to withstand the anticipated $\mathrm{pH}$ range of the debris field. Agglomerated silica-shelled quantum dots maintain their signature for years in basic to neutral environments and 1 to 2 months for acidic solutions. It is possible to produce the particles with methods that scale easily for larger production and provide for size selectivity. The tracers are tolerant of explosive environments, ${ }^{[4]}$ and current results suggest that they are stable at elevated temperatures $\left(100^{\circ} \mathrm{C}\right.$ to $450^{\circ} \mathrm{C}$ ) on the minute time scale (Supplementary Information Fig. S4). The combination of size control and environmental, event, and debris tolerance suggests that the agglomerated silica-shelled particles enable mass tracking through harsh environments.

\section{Conclusions}

Tracer particulates for harsh environments required controllable sizes that maintain their luminescent signature in the local environment. Two methods of particle synthesis were employed to make silica-covered quantum dots with particle sizes from 0.1 to $4 \mu \mathrm{m}$. As local $\mathrm{pH}$ plays a large role on the stability of the silica shell, the tracers were tested over the $\mathrm{pH}$ range from 3 to 13. Basic and neutral environments enhanced the luminescent signature of the tracers on the years' time scale while acidic solutions degraded tracer performance in 40-60 days. Future work entails determination of the florescence stability in environments of interest, such as salinity and chemical exposures. The combination of a tracer that is mass manufacturable, enduring in harsh environments, and tailorable to specific conditions enables the deployment of an elegant solution to mass tracking. These particles enable mass tracking through harsh processes such as chemical explosions, industrial processes, underground environments, oil/gas/fracking fields, nuclear reactors, and geothermal plants.

\section{Acknowledgments}

This research was funded by the National Nuclear Security Administration, Defense Nuclear Nonproliferation Research and Development (NNSA DNN R\&D). The authors acknowledge important interdisciplinary collaboration with scientists and engineers from LANL, LLNL, MSTS, PNNL, and SNL.

\section{Data availability}

The datasets generated during and/or analyzed during the current study are available from the corresponding author on reasonable request.

\section{Declarations}

\section{Conflict of interest}

On behalf of all authors, the corresponding author states that there is no conflict of interest. 


\section{Open Access}

This article is licensed under a Creative Commons Attribution 4.0 International License, which permits use, sharing, adaptation, distribution and reproduction in any medium or format, as long as you give appropriate credit to the original author(s) and the source, provide a link to the Creative Commons licence, and indicate if changes were made. The images or other third party material in this article are included in the article's Creative Commons licence, unless indicated otherwise in a credit line to the material. If material is not included in the article's Creative Commons licence and your intended use is not permitted by statutory regulation or exceeds the permitted use, you will need to obtain permission directly from the copyright holder. To view a copy of this licence, visit http://creativecommons. org/licenses/by/4.0/.

\section{Supplementary Information}

The online version contains supplementary material available at https://doi.org/10.1557/s43579-022-00150-3.

\section{References}

1. W. Jolin, M. Kaminski, Developing Surrogate Far-Field Nuclear Fallout and Its Rapid Decontamination from Aircraft Surfaces, ANL/SSS-19/1 (Argonne National Laboratory, Argonne, IL, 2019)

2. L. Oglesby, N. Künzli, M. Röösli, C. Braun-Fahrländer, P. Mathys, W. Stern, M. Jantunen, A. Kousa, J. Air Waste Manage. Assoc. (2000). https://doi.org/ 10.1080/10473289.2000.10464156

3. R.G. Sinclair, J.B. Rose, S.A. Hashsham, C.P. Gerba, C.N. Haase, Appl. Environ. Microbiol. (2012). https://doi.org/10.1128/AEM.06582-11

4. L. Hubbard, R. Sumner, M. Liezers, T. Cell, C. Reed, N. Uhnak, C. Allen, B. Berry, H. Currah, E. Fuller, E. Kinney, N. Smith, M. Foxe, A. Carman, MRS Commun. (2020). https://doi.org/10.1557/mrc.2020.70

5. A. Amiri, G. Øye, J. Sjöblom, J. Colloids Surf. A (2009). https://doi.org/10. 1016/j.colsurfa.2009.07.050
6. R. Brilmayer, S. Kübelbeck, A. Khalil, M. Brodrecht, U. Kunz, H.J. Kleebe, G. Buntkowsky, G. Baier, A. Andrieu-Brunsen, Adv. Mater. Interfaces (2020). https://doi.org/10.1002/admi.201901914

7. J. Depasse, A. Watillon, J. Colloid Interface Sci. (1970). https://doi.org/10. 1016/0021-9797(70)90235-3

8. M.L. Fisher, M. Colic, M.P. Rao, F.F. Lange, J. Am. Ceram. Soc. (2001). https:// doi.org/10.1111/j.1151-2916.2001.tb00731.x

9. J.W. Goodwin, R.S. Harbron, P.A. Reynolds, Colloid Polym. Sci. (1990). https:// doi.org/10.1007/BF01411109

10. N. Nuryono, D. Miswanda, S.C.W. Sakti, B. Rusdiarso, P.A. Krisbiantoro, N. Utami, R. Otomo, Y. Kamiya, Mater. Chem. Phys. (2020). https://doi.org/ 10.1016/j.matchemphys.2020.123507

11. W. Yan, Z. Zhang, X. Guo, W. Liu, Z. Song, ECS J. Solid State Sci. Technol. (2015). https://doi.org/10.1149/2.0241503jss

12. G. Liu, Y. He, J. Colloid Interface Sci. (2012). https://doi.org/10.1016/j. jcis.2012.08.016

13. P. Mulvaney, L.M. Liz-Marzán, M. Giersig, T. Ung, J. Mater. Chem. (2000). https://doi.org/10.1039/b000136h

14. A. Wolcott, D. Gerion, M. Visconte, J. Sun, A. Schwartzberg, S. Chen, J.Z. Zhang, J. Phys. Chem. B (2006). https://doi.org/10.1021/jp057435z

15. Y. Ma, Y. Li, X, Zhong, Silica coating of luminescent quantum dots prepared in aqueous media for cellular labeling. Mater. Res. Bull. (2014). https://doi.org/10.1016/j.materresbull.2014.08.033

16. M. Runowski, S. Goderski, J. Paczesny, M. Ksiezopolska-Gocalska, A. Ekner-Grzyb, T. Grzyb, J.D. Rybka, M. Giersig, S. Lis, J. Phys. Chem. C (2016). https://doi.org/10.1021/acs.jpcc.6b06644

17. W. Stober, A. Fink, E. Bohn, Controlled growth of monodisperse silica spheres in the micron size range. J. Colloid Interface Sci. (1968). https:// doi.org/10.1016/0021-9797(68)90272-5

18. P.P. Ghimire, M. Jaroniec, J. Colloid Interface Sci. (2021). https://doi.org/ 10.1016/j.jcis.2020.10.014

19. B. Zhao, C. Tian, Y. Zhang, T. Tang, F. Wang, Particuology (2011). https:// doi.org/10.1016/j.partic.2010.07.028

20. M.A. Zwijnenburg, Nanoscale (2012). https://doi.org/10.1039/c2nr30191a

21. H.C. Warad, S.C. Ghosh, B. Hemtanon, C. Thanachayanont, J. Dutta, Sci. Technol. Adv. Mater. (2005). https://doi.org/10.1016/j.stam.2005.03.006

22. G.-J. Lee, H.-C. Chen, J.J. Wu, Int. J. Hydrogen Energy (2019). https://doi. org/10.1016/j.ijhydene.2018.02.041

23. J.F. Reber, K. Meier, J. Phys. Chem. (1984). https://doi.org/10.1021/j1506 68a032

24. J. Pichtel, Appl. Environ. Soil Sci. (2012). https://doi.org/10.1155/2012/ 617236 